\title{
Contribution of Development to Buspirone Effects on REM Sleep: A Preliminary Report
}

\author{
Uma Rao, M.D., Preetam Lutchmansingh, Ph.D., and Russell E. Poland, Ph.D.
}

In order to assess whether development influences the regulation of rapid eye movement (REM) sleep by serotonergic (5-HT) systems, the REM sleep responses to the partial 5-HT $T_{1 A}$ agonist, buspirone, were assessed in 14 normal adolescent and adult volunteers. Subjects were studied on three separate sessions for three consecutive nights. On the second night of each session, subjects received placebo or one of two doses of buspirone $(0.14 \mathrm{mg} /$ $\mathrm{kg}$ and $0.28 \mathrm{mg} / \mathrm{kg}$, orally). Night 3 was considered the "recovery" night. In adolescents, both doses of buspirone significantly delayed REM latency. In contrast, low-dose buspirone had no effect on REM latency in the adults, and there was only a tendency for prolongation of REM latency with the higher dose. Other measures of REM sleep on nights 2 and 3 were comparable between the two groups. These preliminary results suggest that post-synaptic 5-HT $1 A$ acceptor-coupled REM sleep responses, particularly REM latency, may be relatively greater in youngsters than in adults, possibly due to reduced presynaptic input. The findings are discussed in relation to the age-dependent expression of REM sleep changes associated with depression.

[Neuropsychopharmacology 22:440-446, 2000]

(C) 2000American College of Neuropsychopharmacology. Published by Elsevier Science Inc.
KEY WORDS: Adolescents; Adults; Buspirone; Development; REM sleep; Serotonergic

In recent years, a large body of research has provided evidence for continuities in juvenile and adult mood disorders, with similarities in clinical presentation, associated features and natural history of depressive illness (Kovacs 1996). However, maturational variations from child and adolescent to adult depression also have been highlighted, including differences in pharmacologic responses, hypothalamic-pituitary-adrenal system regulation and electroencephalographic (EEG) sleep

From the of Psychiatry (UR, PL, REP), Harbor-UCLA Medical Center, Torrance, CA; and Department of Psychiatry (UR, REP) and Brain Research Institute (UR, REP), UCLA School of Medicine, Los Angeles, CA.

Address correspondence to: Uma Rao, M.D., UCLA Neuropsychiatric Institute, 760 Westwood Plaza, Room 68-237, Los Angeles, CA 90024-1759.

Received April 26, 1999; revised July 16, 1999; accepted September $9,1999$. changes (see Emslie et al. 1997; Rao et al. 1996). EEG sleep changes, particularly with respect to rapid eye movement (REM) sleep variables, have been demonstrated consistently in adult subjects with depression (Benca et al. 1992). Controlled studies in early onset depression, however, have yielded infrequent evidence of the same abnormalities (Rao et al. 1996). The mechanisms for disparity in depression-related EEG sleep changes between youngsters and adults are unclear.

Preclinical studies have shown that pontine cholinergic "REM-on" cells initiate and maintain REM sleep, whereas monoaminergic "REM-off" cells in the dorsal raphe nucleus and the locus coeruleus, through projections to REM activating pontine formations, are inactivated prior to and during REM sleep (for a review, see McCarley et al. 1995). One possibility for developmental differences in the manifestation of REM sleep changes in depression is that the neurotransmitter circuitry involved in REM sleep regulation is not fully mature in youngsters. Thus, shortened REM latency or increased REM activity and density in depression might not be able to fully manifest before adulthood. 
We previously found that the delay in REM latency in response to scopolamine, a non-specific muscarinic cholinergic antagonist, occurs to comparable degrees in both normal adolescents and adults, suggesting that muscarinic cholinergic tone is working in both age groups (McCracken et al. 1997; Poland et al. 1997; Rao et al. 1999a). In fact, the subtle developmental differences observed in REM sleep measures in response to scopolamine revealed that the cholinergic activity may be even greater in adolescents (Rao et al. 1999a). Similarly, the REM sleep response to scopolamine, particularly REM latency, also was relatively intact in adult and adolescent patients with depression (McCracken et al. 1997; Poland et al. 1997). In contrast to scopolamine, adults with major depression show an enhanced shortening of REM latency in response to cholinergic agonists (Berkowitz et al. 1990; Gillin et al. 1978; Hohagen et al. 1993; Sitaram et al. 1978), and one study suggests that this abnormal response also is observed in prepubertal children (Dahl et al. 1994). However, it still remains unclear as to why the majority of studies in depressed youngsters have not shown the typical REM sleep abnormalities, particularly shortened REM latency, which are observed in adult depressed patients.

In order to study this issue further, in this preliminary investigation, sleep patterns in normal adolescents and adults were studied following the administration of buspirone, a partial agonist at serotonin $\left(5-\mathrm{HT}_{1 \mathrm{~A}}\right)$ receptors. Serotonin (5-HT) systems exert their action on REM sleep, at least in part, through post-synaptic 5- $\mathrm{HT}_{1 \mathrm{~A}}$ receptor-mediated hyperpolarization of the mesopontine cholinergic neurons (Leonard and Llinás 1994; Luebke et al. 1992). In adults, REM sleep inhibition has been demonstrated with the administration of buspirone (Seidel et al. 1985), and other 5-HT $1 \mathrm{~A}$ agonists (Driver et al. 1995; Gillin et al. 1994; Lawlor et al. 1991). To our knowledge, there are no investigations examining the effects of $5-\mathrm{HT}_{1 \mathrm{~A}}$ agonists on sleep patterns in adolescents.

\section{METHODS AND MATERIALS}

\section{Participants}

Fourteen subjects between the ages of 14 and 41, eight adolescents (age $\leqslant 20$, six males and two females), and six adults (four males and two females) were studied. The study was approved by the Institutional Review Board, and informed consent for adolescents was obtained from the adolescent as well as the parent. All participants were evaluated for psychopathology with the Structured Clinical Interview for DSM-III-R (SCID) (Spitzer et al. 1986). Also, psychopathology in the firstdegree relatives was assessed, using the subject or parent (in the case of adolescents) as an informant. In addition to the SCID interview, severity of depressive symptoms were rated using the Hamilton Depression Rating Scale
(HDRS) (Hamilton 1960), and the Beck Depression Inventory (BDI) (Beck et al. 1961). The subjects had no personal or family history of a major psychiatric disorder. All participants had HAM-D scores ranging from $0-1$, and BDI scores $<4$. Subjects were medically healthy, as determined by physical examination, full chemistry panel, thyroid function tests, electrocardiogram and urine drug screens.

All participants were free from medication use for at least two weeks. In order to rule out known sleep disorders, a sleep questionnaire was filled-out. Subjects with a personal history of a major sleep disorder or a family history of narcolepsy were excluded from the study. Participants were screened also for the presence of sleep disorder(s) on the first night of the sleep protocol. Subjects were requested to go to bed between 10.30 p.m. and 11.30 p.m. and awake between 6.30 a.m. and 7.30 a.m. for at least one week prior to the study, and a sleep log was maintained prior to and during the study.

\section{Sleep Protocol and Scoring of Sleep Records}

The sleep protocol was a three-condition within-subjects design. Each subject was studied on three separate sessions for three consecutive nights during each session, approximately one week apart between sessions. On all nights, conventional EEG electrodes were attached by 8:00 p.m., and sleep recordings were made from 11:00 p.m. (lights out) to 7:00 a.m.. On night 2 of each three-night session, subjects were administered either placebo or one of two doses of buspirone $(0.14 \mathrm{mg} /$ $\mathrm{kg}$ and $0.28 \mathrm{mg} / \mathrm{kg}$, PO; equivalent to $10 \mathrm{mg}$ and $20 \mathrm{mg}$ in an individual weighing $70 \mathrm{Kg}$ ) at 11:00 p.m. in a double-blind, randomized fashion. Night 3 was considered the recovery or "rebound" night. Examination of sleep logs revealed that there were no significant differences between home and laboratory sleep/wake schedules.

The International 10-20 System was utilized for EEG electrode placement, electromyogram, electrooculogram and electrocardiogram. In order to rule out the presence of sleep disorders, a full sleep polysomnography was performed on the first night, including respiratory, oximetry and leg movement measurements. Bilateral EEG recordings were obtained from left (C3) and right (C4) central leads referenced to the opposite mastoid, $\mathrm{A} 2$ and $\mathrm{A} 1$, as well as to a linked reference (A1 + A2).

Sleep records were coded and scored blindly according to standard criteria (Rechtschaffen and Kales 1968). REM latency was defined as the time between sleep onset (first minute of stage 2 or deeper sleep, followed by at least 9 min of stage 2 or deeper sleep, interrupted by no more than $1 \mathrm{~min}$ of waking or stage 1 ) and the first REM period $\geqslant 3 \mathrm{~min}$ in length. REM latency is reported with and without intervening wake time subtracted. Other REM sleep measures, including REM activity and REM density, and additional sleep variables were scored 
according to the criteria of Kupfer (1976), as was done previously (Poland et al. 1989, 1997; Rao et al 1999a).

\section{Statistical Analysis}

Statistical analyses were performed utilizing three-way analysis of variance (ANOVA) with repeated measures, with adolescent versus adult as the between-subjects factor, and dose (placebo versus buspirone $0.14 \mathrm{mg} / \mathrm{kg}$ versus buspirone $0.28 \mathrm{mg} / \mathrm{kg}$ ) and night (treatment versus recovery) as the within-subject factors. Due to modest sample sizes, based on a priori hypothesis, analyses were restricted to REM sleep variables. Where significant main or interaction effects for group, dose or night were observed, separate analyses were performed, using unpaired and paired t-tests, to locate significant differences. Alpha was set at 0.05. Pearson product-moment correlation coefficients were calculated to examine the relationship between age and change in REM sleep measures on treatment and recovery nights (difference in values between drug and placebo). Logarithmic transformations were performed for REM latency, REM activity and REM duration to normalize variability. Only EEG data from the second and third nights of each three-night session were used in the statistical analyses, the first night being considered as adaptation night.

\section{RESULTS}

\section{REM Latency Responses to Buspirone in Adolescents versus Adults}

REM latency values at baseline and after treatment with buspirone in adolescents and in adults are depicted in Figure 1. Although baseline REM latency was longer in adolescents as compared to adults, there was no significant group difference. Also, REM latency values did not differ significantly between treatment and recovery nights with placebo in either adolescents or adults. Compared to the placebo night, buspirone significantly prolonged REM latency at both doses in adolescents (see Figure 1). In adults, low-dose buspirone had no effect on REM latency, whereas there was a tendency to lengthen REM latency at the high dose (Figure 1). During recovery from buspirone, there was a shortening of REM latency in both groups (Figure 1). The results were essentially the same when intervening wake time was subtracted or when sleep latency on the treatment night was co-varied.

\section{Relationship Between Age and REM Latency Response to Buspirone}

With the low buspirone dose, there was a tendency for younger subjects to have longer REM latency than older
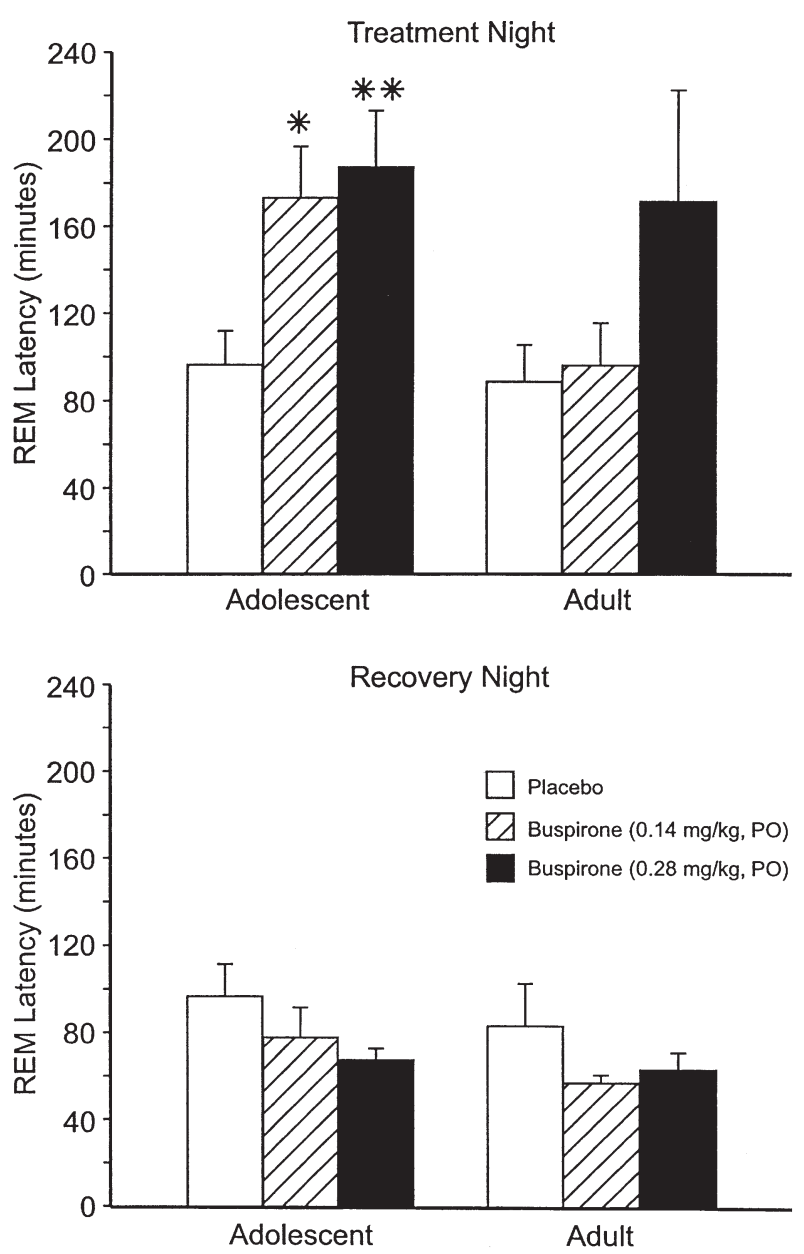

Figure 1. REM latency (Mean \pm SEM) with placebo and buspirone $(0.14 \mathrm{mg} / \mathrm{kg}$ and $0.28 \mathrm{mg} / \mathrm{kg}$, p.o.) administration in adolescents and adults (upper panel). REM latency values on the recovery nights following placebo and buspirone treatments (lower panel). [* $\left.p \leqslant .05 ;{ }^{* *} p \leqslant .005\right]$.

subjects (Pearson $r=-0.46, p \leqslant .10$ ). The correlation co-efficient between change in REM latency and age on the high buspirone dose was -0.02 . On recovery nights, the correlation co-efficients were +0.02 and +0.25 for the low-dose and high-dose buspirone, respectively.

\section{Effect of Buspirone on Other REM Sleep Measures in Adolescents and Adults}

Other REM sleep variables are presented in Table 1. Baseline REM sleep measures were comparable between adolescents and adults. These variables did not differ significantly between treatment and recovery nights with placebo.

First REM Episode. There was a group $\mathrm{x}$ night interaction for REM activity $\left(\mathrm{F}_{1,12}=5.44, p \leqslant .05\right)$. On the treatment night, compared to placebo, buspirone tended to increase REM activity in a dose dependent manner in adolescents (see Table 1). However, these 
differences in REM activity in response to buspirone were not statistically significant. In the adults, REM activity did not change from baseline with either dose. A similar pattern was observed for REM density $\left(\mathrm{F}_{1,12}=\right.$ $7.36, p \leqslant .05)$. On the recovery nights following buspirone treatment, there was a non-significant trend for reduction of REM activity and REM density towards baseline values in adolescents. Although not statistically significant, there was a tendency for buspirone to increase REM duration in a dose dependent manner in adolescents, but not in adults.

All REM Episodes. There was a significant main effect of the night on REM activity $\left(\mathrm{F}_{1,12}=22.34, p \leqslant\right.$ .0001). Compared to the treatment night, REM activity was increased on the recovery night for all three drug conditions, but statistical significance was noted only for the two buspirone doses and for the adolescent group only (Table 1). A significant group $\mathrm{x}$ drug $\mathrm{x}$ night interaction for the REM density was found $\left(\mathrm{F}_{2,11}=4.12\right.$, $p \leqslant .05)$.

A tendency for buspirone to increase REM density in a dose dependent manner was observed on the treatment night in adolescents, but not in adults $\left(\mathrm{t}_{12}=1.86, p \leqslant\right.$ .10 for high buspirone dose). Also, REM density continued to remain high on the recovery night in adolescents, but not in adults $\left(\mathrm{t}_{12}=2.80, p \leqslant .05\right.$ for change in REM density on the recovery nights for both doses).
There was a dose $\mathrm{x}$ night interaction for the REM duration $\left(\mathrm{F}_{2,11}=3.84, p \leqslant .06\right)$ and for REM episodes $\left(\mathrm{F}_{2,11}=\right.$ $7.31, p \leqslant .01)$. Compared to the placebo, buspirone administration suppressed REM sleep in both adolescents and adults, with a return to baseline values on recovery nights. However, statistical significance was noted only in the adolescent group (Table 1).

\section{Relationship between Age and REM Sleep Responses to Buspirone}

Pearson correlation coefficients between age and change in REM sleep variables on the treatment nights revealed marked variability among the measures, but none showed a significant relationship with age. Both phasic REM sleep measures and REM duration during the first REM episode were negatively correlated with age. In contrast to the developmental effect seen with REM latency, buspirone tended to increase REM sleep in younger subjects, specifically with the higher dose ( $\mathrm{r}$ values ranging from -0.16 to -0.40 ). However, when REM sleep for the entire night was examined, buspirone was effective in suppressing tonic REM sleep measures across the age spectrum ( $\mathrm{r}$ values ranging from +0.06 to +0.25$)$. Buspirone dose showed a differential effect on the relationship between age and phasic REM sleep variables $(r=+0.28$ and -0.20 for low and high doses, respectively, for REM activity).

Table 1. REM Sleep Variables (Mean \pm SEM) Following Placebo and Buspirone

\begin{tabular}{|c|c|c|c|c|c|c|}
\hline & \multicolumn{2}{|c|}{ Placebo } & \multicolumn{2}{|c|}{ Buspirone (0.14 mg/kg, p.o.) } & \multicolumn{2}{|c|}{ Buspirone (0.28 mg/kg, p.o.) } \\
\hline & Treatment Night & Recovery Night & Treatment Night & Recovery Night & Treatment Night & Recovery Nigh \\
\hline \multicolumn{7}{|c|}{ First REM episode } \\
\hline \multicolumn{7}{|c|}{ REM activity (units) } \\
\hline Adolescents & $13.2 \pm 5.0$ & $24.7 \pm 5.9$ & $31.2 \pm 11.9$ & $17.5 \pm 5.3$ & $71.5 \pm 34.1$ & $20.0 \pm 7.9$ \\
\hline Adults & $25.7 \pm 9.6$ & $38.7 \pm 11.8$ & $22.4 \pm 7.1$ & $51.9 \pm 13.8$ & $29.1 \pm 11.1$ & $36.6 \pm 9.8$ \\
\hline \multicolumn{7}{|c|}{ REM density (units/min) } \\
\hline Adolescents & $1.2 \pm 0.3$ & $1.5 \pm 0.2$ & $2.0 \pm 0.4$ & $1.5 \pm 0.3$ & $1.9 \pm 0.4$ & $1.3 \pm 0.3$ \\
\hline Adults & $1.5 \pm 0.3$ & $2.3 \pm 0.5$ & $1.5 \pm 0.2$ & $2.6 \pm 0.5^{b}$ & $1.6 \pm 0.4$ & $2.8 \pm 0.8$ \\
\hline \multicolumn{7}{|c|}{ REM duration (min) } \\
\hline Adolescents & $9.1 \pm 2.1$ & $16.0 \pm 3.6$ & $12.6 \pm 4.0$ & $11.0 \pm 2.0$ & $26.9 \pm 8.3$ & $11.3 \pm 3.3$ \\
\hline Adults & $15.0 \pm 3.6$ & $17.7 \pm 5.1$ & $14.6 \pm 4.4$ & $19.0 \pm 2.7$ & $14.7 \pm 3.5$ & $12.7 \pm 6.7$ \\
\hline \multicolumn{7}{|c|}{ All REM episodes } \\
\hline \multicolumn{7}{|c|}{ REM activity (units) } \\
\hline Adolescents & $208.8 \pm 33.5$ & $220.1 \pm 37.9$ & $184.2 \pm 24.9$ & $265.9 \pm 18.3^{b}$ & $212.9 \pm 25.1$ & $250.8 \pm 26.1^{b}$ \\
\hline Adults & $208.2 \pm 30.1$ & $284.9 \pm 23.1$ & $180.5 \pm 19.7$ & $288.0 \pm 45.3$ & $173.4 \pm 46.8$ & $279.4 \pm 30.2$ \\
\hline \multicolumn{7}{|c|}{ REM density (units/min) } \\
\hline Adolescents & $2.5 \pm 0.2$ & $2.5 \pm 0.3$ & $2.8 \pm 0.3$ & $3.1 \pm 0.3^{a}$ & $3.0 \pm 0.3$ & $2.8 \pm 0.2$ \\
\hline Adults & $2.6 \pm 0.3$ & $3.0 \pm 0.2$ & $2.8 \pm 0.2$ & $2.6 \pm 0.3$ & $2.4 \pm 0.5$ & $3.1 \pm 0.5$ \\
\hline \multicolumn{7}{|c|}{ REM duration (min) } \\
\hline Adolescents & $81.1 \pm 8.8$ & $85.1 \pm 6.3$ & $66.8 \pm 5.3$ & $86.3 \pm 3.1^{b}$ & $69.8 \pm 4.1$ & $88.7 \pm 7.0^{b}$ \\
\hline Adults & $80.6 \pm 3.5$ & $96.7 \pm 7.3$ & $63.3 \pm 4.3^{a}$ & $107.5 \pm 8.4^{b}$ & $75.9 \pm 9.0$ & $89.8 \pm 8.7$ \\
\hline \multicolumn{7}{|c|}{ No. of REM episodes } \\
\hline Adolescents & $4.0 \pm 0.3$ & $3.9 \pm 0.2$ & $3.3 \pm 0.3^{a}$ & $3.9 \pm 0.2^{b}$ & $2.9 \pm 0.5^{\mathrm{a}}$ & $4.5 \pm 0.3^{b}$ \\
\hline Adults & $4.0 \pm 0.3$ & $4.0 \pm 0.4$ & $3.7 \pm 0.3$ & $3.8 \pm 0.3$ & $2.8 \pm 0.5$ & $3.8 \pm 0.3$ \\
\hline
\end{tabular}

${ }^{a} p \leqslant .05$, placebo versus buspirone, same night.

${ }^{b} p \leqslant .05$, treatment versus recovery night, same drug and dose. 
On the recovery night, with the exception of total REM density, none of the change scores in REM sleep measures showed a significant correlation with age for either dose ( $\mathrm{r}$ values ranging from -0.22 to +-.29 ). Change in REM density showed a negative relationship with age for both doses of buspirone $(r=-0.63$ for both doses, $p \leqslant .05$ ). As the age increased, there was less rebound increase in REM density on the buspirone recovery night. The results did not change when REM density values on the buspirone treatment night were partialled out $(r=-0.63, p \leqslant .05$ for the low dose; $r=$ $-0.68, p \leqslant .01$ for the high dose).

\section{DISCUSSION}

To our knowledge, this is the first study to examine the effects of a $5-\mathrm{HT}_{1 \mathrm{~A}}$ agonist on sleep patterns in adolescents, and to directly compare and contrast the effects of buspirone on REM sleep measures in adolescents and adults. Buspirone's effect on delaying the onset of REM sleep was more robust in adolescents than in adults. As discussed below, these results, taken together with findings from our previous investigations using scopolamine (McCracken et al. 1997; Poland et al. 1997; Rao et al. 1999a), suggest that the relatively greater input from post-synaptic $5-\mathrm{HT}_{1 \mathrm{~A}}$ systems on the muscarinic cholinergic systems in adolescents may be associated with developmental differences in the manifestation of reduced REM latency observed in depression. However, a direct comparison of buspirone effects on REM latency should be performed in depressed adolescents and adults before drawing such conclusions.

Effect of buspirone on other REM sleep measures was more complex. Overall, buspirone showed differential effects on the suppression of REM sleep in adolescents and adults. During the first REM period, buspirone tended to increase rather than suppress REM sleep in adolescents, with no change observed in adults. However, over the course of the night, buspirone was effective in suppressing REM sleep in both groups. On the rebound night, REM sleep, specifically phasic REM events, was greater in adolescents. It is important to note that REM sleep regulation is complex, and preclinical data suggest that different neuroregulatory systems are involved in the control of tonic and phasic REM sleep measures (Cabeza et al. 1994; Siegel 1994). Furthermore, although 5-HT is implicated in the regulation of REM sleep, the involvement of specific 5-HT receptor subtypes in the various components of REM sleep is unclear. This suggests that $5-\mathrm{HT}_{1 \mathrm{~A}}$ systems may be more involved in the initiation of REM sleep, whereas $5-\mathrm{HT}_{2}$ systems may be more involved in the regulation of REM sleep duration (see Leonard 1996).

Due the modest sample sizes, these results should be considered only preliminary until they are replicated using larger samples. Despite this limitation, the study supports other preclinical and clinical findings in which a delay in REM latency and REM sleep suppression occurred with buspirone administration (Lerman et al. 1986; Mendelson et al. 1990; Monti et al. 1995; Seidel et al. 1985), as well as with a variety of other $5-\mathrm{HT}_{1 \mathrm{~A}}$ agonists (Bjorvatn et al. 1997; Driver et al. 1995; Gillin et al. 1994; Lawlor et al. 1991; Luebke et al. 1992; Monti et al. 1995; Quattrochi et al. 1993; Sanford et al. 1994; Seifritz et al. 1998; Tissier et al. 1994).

The age-related differences in REM latency response to buspirone and in other REM sleep measures do not appear to be due to developmental differences in the pharmacokinetic properties of buspirone. Buspirone probably would be metabolized faster in youngsters than in adults (Rao et al. 1999b). If developmental difference in buspirone metabolism accounted for the agerelated differences in REM sleep responses, buspirone's effect on REM latency and on other REM sleep measures would be expected to be less robust in adolescents than in adults. However, future developmental studies with buspirone or other $5-\mathrm{HT}_{1 \mathrm{~A}}$ agonists should consider measuring serum drug levels. Moreover, the developmental differences in REM sleep responses to buspirone are congruent with preclinical and clinical reports of age-related differences in behavioral and physiological responses to a variety of other psychotropic agents (for a review, see Teicher and Baldessarini 1987).

One possibility for the augmented delay in the appearance of REM sleep following buspirone administration in adolescents might be due to increased sensitivity of post-synaptic $5-\mathrm{HT}_{1 \mathrm{~A}}$ acceptor-coupled systems in youngsters, possibly due to reduced presynaptic input. Further, one possibility for the reduced 5-HT neurotransmission in youngsters is increased activity of the presynaptic autoreceptors. The autoreceptor-mediated negative feedback mechanism appears to be engaged when the neurons are firing at a relatively high rate, i.e., during waking (Fornal et al. 1994). During periods when the 5-HT neurons are relatively inactive (for example, during sleep), the autoreceptor-coupled mechanism becomes disengaged and has little influence on their spontaneous activity (Fornal et al. 1996). It is possible that, under normal baseline conditions when the supersensitive autoreceptors are dormant during sleep, the up-regulated post-synaptic $5-\mathrm{HT}_{1 \mathrm{~A}}$ systems are more active in adolescents, resulting in increased 5-HT neurotransmission. If the net baseline $5-\mathrm{HT}_{1 \mathrm{~A}}$ neurotransmission, which is inhibitory to REM sleep, is indeed enhanced or maintained longer during sleep in adolescents, this could account for the relatively longer REM latency typically observed in normal youngsters and, possibly, the inability of depressed adolescents to manifest shortened REM latency.

Despite the post-synaptic "supersensitivity," the net 
baseline $5-\mathrm{HT}_{1 \mathrm{~A}}$ acceptor-coupled neurotransmission may be reduced in adolescents as compared to adults which might underlie the poor response to antidepressants in youngsters (Emslie et al. 1997). In addition to the possibility of enhanced baseline sensitivity of post-synaptic $5-\mathrm{HT}_{1 \mathrm{~A}}$ systems, other mechanisms might be involved in restraining the appearance of REM sleep in adolescents. One possibility is greater slow-wave sleep pressure than REM sleep pressure in adolescents (Borbély 1982).

In summary, these preliminary results suggest that developmental differences in $5-\mathrm{HT}_{1 \mathrm{~A}}$ receptor regulation of REM sleep might be associated with reduced prevalence of REM sleep abnormalities in depressed adolescents and, possibly, diminished antidepressant efficacy. In order to further clarify the role of developmental influences on 5-HT regulation of REM sleep and their relationship to depressive illness, future investigations should include larger samples of normal controls and depressed patients from various age groups.

\section{ACKNOWLEDGMENTS}

This study was supported in part by the NIMH Scientist Development Award MH01419 (to UR), NIMH Research Scientist Development Award MH00534 (to REP), NIMH Research Center on the Psychobiology of Ethnicity MH47193, MH34471, and NIH General Clinical Research Center Grant RR00425. The authors thank Manny Madamba for technical assistance, Maria Paz Dulay for literature searches, and Debbie Hanaya for administrative support.

\section{REFERENCES}

Beck AT, Ward CH, Mendelson M, Muck M, Erbaugh J (1961): An inventory for measuring depression. Arch Gen Psychiatry 4:561-571

Benca RM, Obermeyer WH, Thisted RA, Gillin JC (1992): Sleep and psychiatric disorders. Arch Gen Psychiatry 49:651-668

Berkowitz A, Sutton L, Janowsky DS, Gillin JC (1990): Pilocarpine, an orally active muscarinic cholinergic agonist, induces REM sleep and reduces delta sleep in normal volunteers. Psychiatry Res 33:113-119

Bjorvatn B, Fagerland S, Eid T, Ursin R (1997): Sleep/waking effects of selective 5-HT1A receptor agonist given systemically as well as perfused in the dorsal raphe nucleus in rats. Brain Res 770:81-88

Borbély AA (1982): A two process model of sleep regulation. Human Neurobiol 1:195-204

Cabeza RDJ, Zoltoski RK, Gillin JC (1994): Biochemical pharmacology of sleep. In Chokroverty S (ed), Sleep Disorders Medicine. Boston, MA, Butterworth-Heinemann, pp 37-56

Dahl RE, Ryan ND, Perel J, Birmaher B, Al-Shabbout M, Nelson B, Puig-Antich J (1994): Cholinergic REM induction test with arecoline in depressed children. Psychiatry Res 51:269-282
Driver HS, Flanigan MJ, Bentley AJ, Luus HG, Shapiro CM, Mitchell D (1995): The influence of ipsapirone, a 5-HT1A agonist, on sleep patterns of healthy subjects. Psychopharmacology 117:186-192

Emslie GJ, Rush AJ, Weinberg WA, Kowatch RA, Hughes CW, Carmody T, Rintelmann J (1997): A double-blind, randomized, placebo-controlled trial of fluoxetine in children and adolescents with depression. Arch Gen Psychiatry 54:1031-1037

Fornal CA, Litto WJ, Metzler CW, Marrousu F, Tada K, Jacobs BL (1994): Single-unit responses of serotonergic dorsal raphe neurons to $5 \mathrm{HT}_{1 \mathrm{~A}}$ agonist and antagonist drug administration in behaving cats. J Pharmacol Expt Ther 270:1345-1358

Fornal CA, Metzler CW, Gallegos RA, Veasey SC, McCreary AC, Jacobs BL (1996): WAY-100635, a potent and selective 5-hydroxtryptamine $\mathrm{e}_{1 \mathrm{~A}}$ antagonist, increases serotonergic neuronal activity in behaving cats: Comparison with (S)-WAY-10135. J Pharmacol Expt Ther 2773:752762

Gillin JC, Sitaram N, Mendelson WB, Wyatt RJ (1978): Physostigmine alters onset but not duration of REM sleep in man. Psychopharmacology 58:111-114

Gillin JC, Wojciech J, Valladares-Neto DDC, Golshan S, Lardon M, Stahl SM (1994): Inhibition of REM sleep by ipsapirone, a $5 \mathrm{HT}_{\mathrm{A}}$ agonist, in normal volunteers. Psychopharmacology 116:433-436

Hamilton M (1960): A rating scale for depression. J Neurol Neursurg Psychiatry 25:56-62

Hohagen F, Riemann D, Spiegel R, Holzhauer M, Berger M (1993): Influence of the cholinergic agonist SDZ 210-086 on sleep in healthy subjects. Neuropsychopharmacology 9:225-232

Kovacs M (1996): Presentation and course of major depressive disorder during childhood and later years of the life span. J Am Acad Child Adolesc Psychiatry 35:705715

Kupfer D (1976): REM latency: a psychobiologic marker for primary depressive disease. Biol Psychiatry 11:159-174

Lawlor BA, Newhouse PA, Balkin TJ, Molchen SE, Mellow AM, Murphy DL, Sunderland TA (1991): A preliminary study of the effects of night time administration of the serotonin agonist, $\mathrm{m}-\mathrm{CPP}$, on sleep architecture and behavior in healthy volunteers. Biol Psychiatry 29:281286

Leonard BE (1996): Serotonin receptors and their function in sleep, anxiety disorders and depression. Psychother Psychosom 65:66-75

Leonard CS, Llinás R (1994): Serotonergic and cholinergic inhibition of mesopontine cholinergic neurons controlling REM sleep: An in vitro electrophysiological study. Neurosciences 59:309-330

Lerman JA, Kaitin KI, Dement WC, Peroutka SJ (1986): The effects of buspirone on sleep in the rat. Neurosci Lett 72:64-68

Luebke JI, Greene RW, Semba K, Kamondi A, McCarley RW, Reiner PB (1992): Serotonin hyperpolarizes cholinergic low-threshold burst neurons in the rat laterodorsal tegmental nucleus in vitro. Proc Natl Acad Sci USA 89:743747

McCarley RW, Greene RW, Rainnie D, Portas CM (1995): 
Brainstem neuromodulation and REM sleep. Neurosciences 7:341-354

McCracken JT, Poland RE, Lutchmansingh P, Edwards C (1997): Sleep electroencephalographic abnormalities in adolescent depressives: Effects of scopolamine. Biol Psychiatry 42:577-584

Mendelson WB, Martin JV, Rapoport DM (1990): Effects of buspirone on sleep and respiration. Am Rev Respir Dis 141:1527-1530

Monti JM, Jantos H, Silveira R, Reyes-Parada M, Scorza C (1995): Sleep and waking in 5, 7-DHT-lesioned or (-)pindolol-pretreated rats after administration of buspirone, ipsapirone, or gepirone. Pharmacol Biochem Behav 52:305-312

Poland RE, McCracken JT, Lutchmansingh P, Lesser IM, Tondo L, Edwards C, Boone KB, Lin K-M (1997): Differential response of rapid eye movement sleep to cholinergic blockade by scopolamine in currently depressed, remitted, and normal control subjects. Biol Psychiatry 41:929-938

Poland RE, Tondo L, Rubin RT, Trelease RB, Lesser IM (1989): Differential effects of scopolamine on nocturnal cortisol secretion, sleep architecture, and REM latency in normal volunteers: Relation to sleep and cortisol abnormalities in depression. Biol Psychiatry 25:403-412

Quattrochi JJ, Mamelak AN, Binder D, Williams J, Hobson JA (1993): Dose-related suppression of REM sleep and PGO waves by the serotonin-1 agonist eltoprazine. Neuropsychopharmacology 8:7-13

Rao U, Dahl RE, Ryan ND, Birmaher B, Williamson DE, Giles DE, Rao R, Kaufman J, Nelson B (1996): The relationship between longitudinal clinical course, sleep and cortisol changes in adolescent depression. Biol Psychiatry 40:474-484

Rao U, Lutchmansingh P, Poland RE (1999a): Age-related effects of scopolamine on REM sleep regulation in normal control subjects: Relationship to sleep abnormalities in depression. Neuropsychopharmacology 21:723730
Rao U, McCracken JT, Poland RE (1999b): Principles of pharmacokinetics and pharmacodynamics. In Ananth J (ed), Psychopharmacology and Treatment of Psychiatric Disorders. New Delhi, India, Jaypee Brothers, pp 77-93

Rechtschaffen A, Kales A (1968): A Manual of Standardized Terminology, Techniques and Scoring System for Sleep Stages of Human Subjects. Los Angeles, CA, Brain Information Service/Brain Research Institute, UCLA

Sanford LD, Ross RJ, Seggos AE, Morrison AR, Ball WA, Mann GL (1994): Central administration of two 5-HT receptor agonists: effect on REM sleep initiation and PGO waves. Pharmacol Biochem Behav 49:93-100

Seidel WF, Cohen SA, Bliwise NG, Dement WC (1985): Buspirone: An anxiolytic without sedative effect. Psychopharmacology 87:371-373

Seifritz E, Gillin JC, Rapaport MH, Kelsoe JR, Bhatti T, Stahl SM (1998): Sleep electroencephalographic response to muscarinic and serotonin ${ }_{1 \mathrm{~A}}$ receptor probes in patients with major depression and in normal controls. Biol Psychiatry 44:21-33

Siegel JM (1994): Brainstem mechanisms generating REM sleep. In Kryger MH, Roth T, Dement WC (eds), Principles and Practice of Sleep Medicine. Philadelphia, PA, W.B. Saunders Company, pp 125-144

Sitaram N, Moore AM, Gillin JC (1978): Induction and resetting of REM sleep rhythm in normal man by arecholine: Blockade by scopolamine. Sleep 1:83-90

Spitzer RL, Williams JBW, Gibbons M (1986): The Structured Clinical Interview for DSM-III-R (SCID). New York, NY, New York State Psychiatric Institute

Teicher MH, Baldessarini RJ (1987): Developmental pharmacodynamics. In Popper C (ed), Psychiatric Pharmacosciences of Children and Adolescents. Washington, DC, American Psychiatric Press, pp 47-79

Tissier M-H, Lainey E, Fattaccini C-M, Hamon M, Adrien J (1994): Effects of ipsapirone, a 5-HT1a agonist, on sleep/wakefulness cycles: Probable post-synaptic action. J Sleep Res 103-109 